\title{
Predictive Risk Factors for Early Recurrence of Stage pllIA-N2 Non-Small Cell Lung Cancer
}

\author{
Qiongjie $\mathrm{Yu}^{*}$ \\ Xuedan Du* \\ Zhen Fang \\ Xiaolu Mao (D) \\ Jinting Wu \\ Bin Wang \\ Wenfeng $\mathrm{Li}$
}

Department of Oncology, The First Affiliated Hospital of Wenzhou Medical University, Wenzhou, Zhejiang, People's Republic of China

*These authors contributed equally to this work
Correspondence: Wenfeng $\mathrm{Li}$

Department of Oncology, The First Affiliated Hospital of Wenzhou Medical University, Wenzhou, Zhejiang, People's Republic of China

Email Iwf720325@I26.com
Purpose: Inflammatory biomarkers and clinical pathological factors have been reported to predict survival of patients with non-small cell lung cancer (NSCLC). The goal of this study was to identify risk factors for early recurrence in patients with pIIIA-N2 NSCLC who had undergone radial resection.

Methods: A retrospective analysis was conducted on 238 patients with pIIIA-N2 NSCLC who underwent surgical treatment at the First Affiliated Hospital of Wenzhou Medical University between December 2006 and August 2018. The early recurrence (ER) group included patients who recurred within one year of curative resection, while the non-early recurrence (NER) group included patients who did not recurrence or recurrence beyond one year. The univariate and multivariate Cox proportional risk analyses were used to identify prognostic factors associated with early recurrence, while the chi-square test was used for categorical data. Overall survival and recurrence-free survival were assessed by Kaplan-Meier estimates.

Results: A total of 69 patients experienced an early recurrence, while the remaining 169 patients did not relapse within one year. ER patients had a much worse prognosis than NER patients, with median survival times of 20.6 and 83.1 months, respectively. Multivariate analysis showed that smoking status, tumor size, metastatic lymph node ratio (LNR) and platelet-to-lymphocyte ratio (PLR) were independent risk factor of early recurrence. Patients with early recurrence were more likely to develop bone metastases.

Conclusion: Smoking history, large tumour size, and elevated LNR and PLR values in pIIIA-N2 NSCLC patients after complete resection may have a significant risk of early recurrence. Based on these independent risk indicators, this prediction model may successfully predict early recurrence and advise individual treatment.

Keywords: non-small cell lung cancer, early recurrence, risk factors, inflammatory biomarkers, prognosis

\section{Introduction}

Lung cancer has long been thought to be the leading cause of cancer-related deaths. ${ }^{1}$ non-small cell lung cancer (NSCLC) is the most common type of lung cancer, accounting for about $85 \%$ of all cases. Within NSCLC, $15 \%$ of patients were diagnosed with stage pIIIA-N2 disease. ${ }^{2,3}$ pIIIA-N2 NSCLC is locally progressed NSCLC with heterogeneity. The optimal treatment of NSCLC is still up for debate. $^{4-7}$ The main treatment for resectable pIIIA-N2 NSCLC is surgery, however, survival following resection is unsatisfactory, with a 5-year Overall survival (OS) rate ranging from $10 \%$ to $47.4 \%{ }^{5,8-14}$ Early postoperative recurrence is the greatest stumbling block to long-term survival, thus predicting early recurrence should help doctors choose the best treatment and so prolong longevity. 
Some studies have found clinical and pathologic factors can be effective predictors for stage pIIIA-N2 NSCLC, such as age, ${ }^{15}$ smoking status, ${ }^{16}$ histological subtype,${ }^{17}$ tumor size, ${ }^{18}$ metastatic lymph node ratio (LNR), ${ }^{15,16}$ $\mathrm{N}$ status, ${ }^{15,19}$ histological differentiation degree. ${ }^{15}$ Systemic inflammatory responses have been linked to tumor development, invasion and metastasis in recent years. ${ }^{20-22}$ It has been revealed that inflammation-based scores and nutrition index such as neutrophil-to-lymphocyte ratio (NLR), ${ }^{23}$ lymphocyte-to-monocyte ratio (LMR), ${ }^{24}$ platelet-to-lymphocyte ratio (PLR), ${ }^{25,26}$ C-reactive protein-to-albumin ratio (CAR), ${ }^{27}$ advanced lung cancer inflammation index (ALI), ${ }^{28}$ Systemic immune-inflammation index (SII), ${ }^{29}$ and prognostic nutritional index $(\mathrm{PNI})^{30}$ are related to the recurrence and prognosis of NSCLC. However, few studies have looked into the link between these variables and early recurrence in pIIIA-N2 NSCLC patients, therefore more research is needed.

In this study, we systematically evaluated the influence of clinical, pathologic, and inflammatory markers on the early recurrence and prognosis of stage pIIIA-N2 NSCLC after surgery.

\section{Materials and Methods}

\section{Patients}

The study was carried out in compliance with the Declaration of Helsinki and was approved by the ethics committee of the First Affiliated Hospital of Wenzhou Medical University. We screened 310 patients with pathologically verified IIIA-N2 NSCLC (according to version 8 of the International Association for the Study of Lung Cancer TNM Staging System) who had resection at the First Affiliated Hospital of Wenzhou Medical University between December 2006 and August 2018. 238 patients were finally enrolled after excluding those who were lost to follow-up within one year, had partial data missing, had received neoadjuvant therapy, had a second primary tumor, and had been diagnosed with active systemic inflammation or were taking immunosuppressants. The early recurrence (ER) group included patients who relapsed within one year of surgery, whereas the non-early recurrence (NER) group included patients who relapsed after one year and did not relapse at the last follow-up (Figure 1).

\section{Data Collection}

Clinical pathological data including gender, age, smoking status, body mass index, tumor localization, surgery type, histological subtype, pathological tumor size, N status, LNR, postoperative adjuvant therapy, preoperative inflammatory biomarkers, such as NLR, LMR, PLR, ALI, SII, and PNI. Based on the lymph node reclassification of the International Association for the Study of Lung Cancer (IASLC), we categorized these patients into three groups: pN2al (single $\mathrm{N} 2$ station with skip metastases), pN2a2 (single N2 with N1 station) and $\mathrm{pN} 2 \mathrm{~b}$ (multiple $\mathrm{N} 2$ station involvement). The LNR was calculated as the proportion of metastatic lymph nodes to all dissected lymph nodes. All inflammatory marker values were determined using information from the most recent preoperative blood tests, usually within a week before surgery. NLR and PLR were calculated by dividing the number of neutrophils and platelets by the number of lymphocytes. ALI was calculated by multiplying BMI by serum albumin/NLR. SII was a novel systemic immuneinflammation index which was calculated by multiplying neutrophils and platelets followed by dividing lymphocytes, and PNI was an indicator of immunonutritional status which was calculated by combining albumin with 5 times the absolute number of lymphocytes.

\section{Postoperative Follow-Up Evaluation}

Lab tests, including routine examination, blood biochemical measurement, and tumor indicators, were performed every 1 to 3 months during follow-up examinations after hospital discharge. During the first two years, imaging examinations such as ultrasound and computed tomography (CT) are conducted every three months, and then every six months for the next three years. CT, brain magnetic resonance imaging (MRI), bone scan, and positron emission tomography (PET) were used to evaluate recurrent or metastatic disease when signs of recurrence appeared. Doctors diagnosed recurrence based on clinical symptoms and imaging examination results, and if necessary, a pathology examination was undertaken.

\section{Statistical Analysis}

The main endpoint of this study is recurrence-free survival (RFS) which was defined as the time from the date of surgery to the date of recurrence or distal metastasis. If no events have occurred until the last follow-up, RFS is calculated as the interval between surgery and the last follow-up date. OS is the secondary endpoint, it was defined as the time from surgery to either death from any cause or last follow up. The Yorden index (sensitivity + specificity -1) and the area under the curve (AUC) were calculated by plotting the receiver operating characteristic 


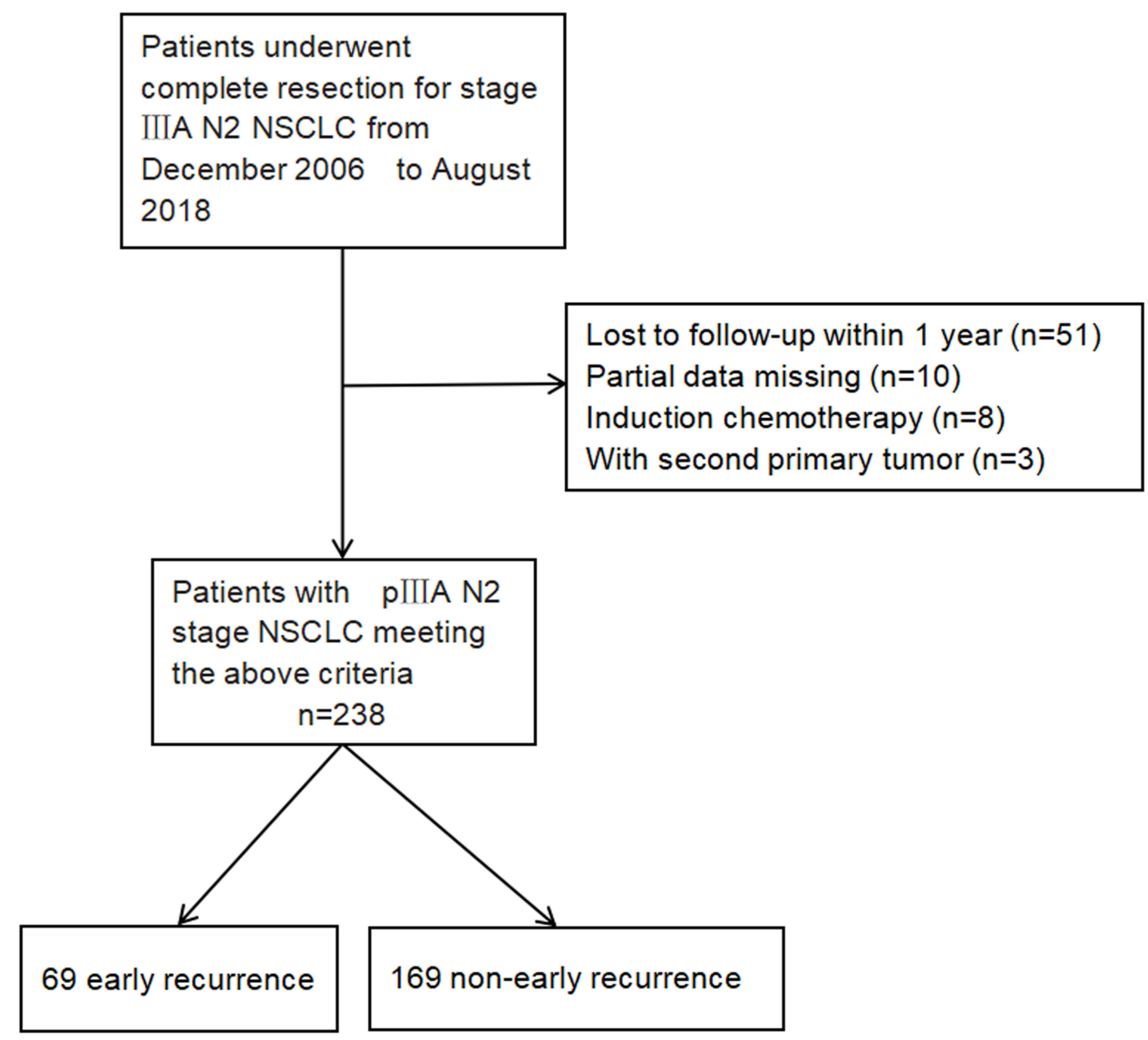

Figure I Flow chart of eligible patients enrolled in this study.

(ROC) curves of patients' risk factor levels. Optimal thresholds for preoperative risk factors were determined and continuous variables were converted to categorical variables. Because of the substantial discrepancy in patient numbers in the two groups separated by the Optimal thresholds, the LMR, ALI and PNI were finally divided into two groups by the median values. AUC values obtained using ROC curves were also used to evaluate the ability of risk factors and the prediction model to predict early recurrence. The significant differences between categorical variables were compared using Pearson's Chi-squared test or Fisher's exact test. Univariate and multivariate Cox regression analyses were performed to estimate the relationship between each factor and the RFS. The independent impact factors and hazard ratios (HR) were obtained by multivariate Cox analysis. For each risk factor, the risk score of control group (the group with smaller value) was defined as 0 points, and the risk scores of other groups were defined as rounded HR values. The total risk score is the sum of the actual scores of all independent impact factors and based on this patients are classified as low-, medium- and high-risk groups. The survival curves of RFS and OS were estimated using the Kaplan-Meier method, the Log rank test was used for comparisons. Two-sided $\mathrm{P}$ values less than 0.05 were considered statistically significant. All statistical analyses were conducted using the IBM SPSS statistics software package, version 26.0.

\section{Results}

\section{Patient Characteristics}

The baseline characteristics of the patients are shown in Table 1. A total of 238 individuals were included in our study, with 132 (55.5\%) males and 106 (44.5\%) females. The median age was 63 years old (range 39-83). At the time of diagnosis, $18.5 \%$ of patients were overweight, according to the WHO BMI classification. Lobectomies were performed in $95 \%$ of patients. Lung adenocarcinoma accounts for more than $70 \%$ of cases. Adjuvant chemotherapy was accepted by $58.4 \%$ of patients after surgery, while $15.5 \%$ of patients with genetic mutations received targeted therapy. The median follow-up time 
Table I Baseline Characteristics of All Patients

\begin{tabular}{|c|c|c|c|c|c|}
\hline Variables & & $\begin{array}{l}\text { All Patients } \\
\mathbf{N}=\mathbf{2 3 8}\end{array}$ & $\begin{array}{l}E R \\
N=69\end{array}$ & $\begin{array}{l}\text { NER } \\
N=169\end{array}$ & $P$ value \\
\hline Gender, n (\%) & $\begin{array}{l}\text { Male } \\
\text { Female }\end{array}$ & $\begin{array}{l}132(55.5) \\
106(44.5)\end{array}$ & $\begin{array}{l}45(65.2) \\
24(34.8)\end{array}$ & $\begin{array}{l}87(51.5) \\
82(48.5)\end{array}$ & 0.053 \\
\hline Age, n (\%) & $\begin{array}{l}\leq 65 \\
>65\end{array}$ & $\begin{array}{l}160(67.2) \\
78(32.8)\end{array}$ & $\begin{array}{l}43(62.3) \\
26(37.3)\end{array}$ & $\begin{array}{l}117(69.2) \\
52(30.8)\end{array}$ & 0.303 \\
\hline Smoking status, n (\%) & $\begin{array}{l}\text { Yes } \\
\text { No }\end{array}$ & $\begin{array}{l}82(34.5) \\
156(65.5)\end{array}$ & $\begin{array}{l}32(46.4) \\
37(53.6)\end{array}$ & $\begin{array}{l}50(29.6) \\
119(70.4)\end{array}$ & 0.013 \\
\hline Body mass index, kg/m2, n (\%) & $\begin{array}{l}<18.5 \\
18.5-25 \\
\geq 25\end{array}$ & $\begin{array}{l}16(6.7) \\
178(74.8) \\
44(18.5)\end{array}$ & $\begin{array}{l}7(10.1) \\
53(76.8) \\
9(13.0)\end{array}$ & $\begin{array}{l}9(5.3) \\
125(74.0) \\
35(20.7)\end{array}$ & 0.192 \\
\hline Tumor localization, n (\%) & $\begin{array}{l}\text { Left lung } \\
\text { Right lung }\end{array}$ & $\begin{array}{l}95(40.0) \\
143(60.0)\end{array}$ & $\begin{array}{l}26(37.7) \\
43(62.3)\end{array}$ & $\begin{array}{l}69(40.8) \\
100(59.2)\end{array}$ & 0.653 \\
\hline Surgery type, n (\%) & $\begin{array}{l}\text { Open } \\
\text { VATS }\end{array}$ & $\begin{array}{l}83(34.9) \\
155(65.1)\end{array}$ & $\begin{array}{l}32(46.4) \\
37(53.6)\end{array}$ & $\begin{array}{l}51(30.2) \\
118(69.8)\end{array}$ & 0.017 \\
\hline Extent of surgical resection, $\mathrm{n}(\%)$ & $\begin{array}{l}\text { Wedge resection } \\
\text { Segmentectomy } \\
\text { Lobectomy } \\
\text { Pneumonectomy }\end{array}$ & $\begin{array}{l}\text { I }(0.4) \\
\text { I }(0.4) \\
226(95.0) \\
\text { I0 (4.2) }\end{array}$ & $\begin{array}{l}0(0) \\
0(0) \\
66(95.7) \\
3(4.3)\end{array}$ & $\begin{array}{l}\text { I }(0.6) \\
\text { I }(0.6) \\
160(94.7) \\
7(4.1)\end{array}$ & 0.843 \\
\hline Histological subtype, n (\%) & $\begin{array}{l}\mathrm{AD} \\
\mathrm{SQ} \\
\text { Other }\end{array}$ & $\begin{array}{l}170(71.4) \\
60(25.2) \\
8(3.4)\end{array}$ & $\begin{array}{l}44(63.8) \\
21(30.4) \\
4(5.8)\end{array}$ & $\begin{array}{l}126(74.6) \\
39(23.1) \\
4(2.4)\end{array}$ & 0.168 \\
\hline Tumor size, cm, n (\%) & $\begin{array}{l}\leq 2.95 \\
>2.95\end{array}$ & $\begin{array}{l}104(43.7) \\
134(56.3)\end{array}$ & $\begin{array}{l}17(24.6) \\
52(75.4)\end{array}$ & $\begin{array}{l}87(51.5) \\
82(48.5)\end{array}$ & 0.0001 \\
\hline $\mathrm{N}$ status, $\mathrm{n}(\%)$ & $\begin{array}{l}\mathrm{pN} 2 \mathrm{al} \\
\mathrm{pN} 2 \mathrm{a} 2 \\
\mathrm{pN} 2 \mathrm{~b}\end{array}$ & $\begin{array}{l}72(30.3) \\
46(19.3) \\
120(50.4)\end{array}$ & $\begin{array}{l}12(17.4) \\
18(26.1) \\
39(56.5)\end{array}$ & $\begin{array}{l}60(35.5) \\
28(16.6) \\
81(47.9)\end{array}$ & 0.016 \\
\hline The number of examined lymph nodes & $\begin{array}{l}\leq 10 \\
>10\end{array}$ & $\begin{array}{l}65(27.3) \\
173(72.7)\end{array}$ & $\begin{array}{l}14(20.3) \\
55(79.7)\end{array}$ & $\begin{array}{l}5 I(30.2) \\
118(69.8)\end{array}$ & 0.120 \\
\hline LNR, n (\%) & $\begin{array}{l}\leq 0.16 \\
>0.16\end{array}$ & $\begin{array}{l}77(32.4) \\
|6|(67.6)\end{array}$ & $\begin{array}{l}15(21.7) \\
54(78.3)\end{array}$ & $\begin{array}{l}62(36.7) \\
107(63.3)\end{array}$ & 0.025 \\
\hline Adjuvant therapy, n (\%) & $\begin{array}{l}\text { No } \\
\text { Chemotherapy } \\
\text { Targeted therapy }\end{array}$ & $\begin{array}{l}62(26.1) \\
139(58.4) \\
37(15.5)\end{array}$ & $\begin{array}{l}22(31.9) \\
40(58.0) \\
7(10.1)\end{array}$ & $\begin{array}{l}40(23.7) \\
99(58.6) \\
30(17.8)\end{array}$ & 0.213 \\
\hline NLR, n (\%) & $\begin{array}{l}\leq 2.51 \\
>2.51\end{array}$ & $\begin{array}{l}147(61.8) \\
91(38.2)\end{array}$ & $\begin{array}{l}34(49.3) \\
35(50.7)\end{array}$ & $\begin{array}{l}113(66.9) \\
56(33.1)\end{array}$ & 0.011 \\
\hline LMR, n (\%) & $\begin{array}{l}\leq 3.54 \\
>3.54\end{array}$ & $\begin{array}{l}119(50) \\
119(50)\end{array}$ & $\begin{array}{l}40(58.0) \\
29(42.0)\end{array}$ & $\begin{array}{l}79(46.7) \\
90(53.3)\end{array}$ & 0.116 \\
\hline PLR, n (\%) & $\begin{array}{l}\leq 139 \\
>139\end{array}$ & $\begin{array}{l}|2|(50.8) \\
117(49.2)\end{array}$ & $\begin{array}{l}23(33.3) \\
46(66.7)\end{array}$ & $\begin{array}{l}98(58.0) \\
7 \mid(42.0)\end{array}$ & 0.001 \\
\hline ALI, n (\%) & $\begin{array}{l}\leq 42.44 \\
>42.44\end{array}$ & $\begin{array}{l}119(50.0) \\
119(50.0)\end{array}$ & $\begin{array}{l}44(63.8) \\
25(36.2)\end{array}$ & $\begin{array}{l}75(44.4) \\
94(55.6)\end{array}$ & 0.007 \\
\hline SII, n (\%) & $\begin{array}{l}\leq 327 \\
>327\end{array}$ & $\begin{array}{l}63(26.5) \\
175(73.5)\end{array}$ & $\begin{array}{l}8(11.6) \\
61(88.4)\end{array}$ & $\begin{array}{l}55(32.5) \\
114(67.5)\end{array}$ & 0.001 \\
\hline
\end{tabular}

(Continued) 
Table I (Continued).

\begin{tabular}{|l|l|l|l|l|l|}
\hline \multicolumn{2}{|l|}{ Variables } & $\begin{array}{l}\text { All Patients } \\
\text { N=238 }\end{array}$ & $\begin{array}{l}\text { ER } \\
\text { N=69 }\end{array}$ & $\begin{array}{l}\text { NER } \\
\text { N=169 }\end{array}$ \\
\hline PNI, n (\%) & $\leq 48.6$ & $119(50.0)$ & $36(52.2)$ & $83(49.1)$ & 0.668 \\
& $>48.6$ & $119(50.0)$ & $33(47.8)$ & $86(50.9)$ & \\
\hline
\end{tabular}

Abbreviations: ER, early recurrence; NER, non-early recurrence; VATS, video-assisted thoracoscopic surgery; AD, adenocarcinoma; SQ, squamous cell carcinoma; LNR, lymph node ratio; NLR, neutrophil-to-lymphocyte ratio; LMR, lymphocyte-to-monocyte ratio; PLR, platelet-to-lymphocyte ratio; ALI, advanced lung cancer inflammation index; SII, systemic immune-inflammation index; PNI, prognostic nutritional index.

was 43.5 months (range 2-170). During this period, ER occurred in 69 patients $(29.0 \%)$ whereas the remaining 169 patients who either recurred after 1 year from surgery $(n=109)$ or did not recur $(n=60)$ were assigned to the NER group. The optimal thresholds according to ROC curve analyses of age, tumor size, LNR, NLR, PLR and SII were 65 years $[\mathrm{AUC}=0.535(95 \% \mathrm{CI}=0.53-0.616)$, sensitivity $=0.377, \quad$ specificity $=0.692, \quad \mathrm{p}=0.403], \quad 2.95 \mathrm{~cm}$ [AUC $=0.634(95 \% \mathrm{CI}=0.558-0.710)$, sensitivity $=0.507$, specificity $=0.669, \mathrm{p}=0.001], \quad 0.16 \quad[\mathrm{AUC}=0.575 \quad(95 \%$ $\mathrm{CI}=0.497-0.653), \quad$ sensitivity $=0.783, \quad$ specificity $=0.367$, $\mathrm{p}=0.071], 2.51[\mathrm{AUC}=0.588(95 \% \mathrm{CI}=0.507-0.669)$, sensitivity $=0.507, \quad$ specificity $=0.667, \quad \mathrm{p}=0.033], \quad 139$ [AUC $=0.623(95 \% \mathrm{CI}=0.546-0.701)$, sensitivity $=0.667$, specificity $=0.580, \mathrm{p}=0.003]$ and 327 [AUC $=0.605(95 \%$ $\mathrm{CI}=0.530-0.680), \quad$ sensitivity $=0.884, \quad$ specificity $=0.325$, $\mathrm{p}=0.011]$, respectively. The selected cut-off values of LMR, ALI and PNI were their median values of 3.54, 42.44 and 48.6. Significant differences between the ER and NER groups were observed in the smoking status $(\mathrm{p}=0.013)$, surgery type $(\mathrm{p}=0.017)$, tumor size $(\mathrm{p}=0.0001)$, lymph node metastases $(\mathrm{p}=0.016)$, LNR $(p=0.025), \quad$ NLR $\quad(p=0.011), \quad$ PLR $\quad(p=0.001), \quad$ ALI $(\mathrm{p}=0.007)$ and SII $(\mathrm{p}=0.001)$.

\section{Univariate and Multivariate Analysis of Risk Factors for Early Recurrence}

The results of univariate analysis using a Cox proportional hazard regression model for ER and NER groups are shown in Table 2. In univariate analyses, gender, smoking status, tumor size, surgery type, lymph node metastases, LNR, NLR, PLR, ALI and SII were clearly associated with early recurrence $(\mathrm{p}<0.05)$. After that, we used these risk factors in multivariate analysis, which revealed a correlation in univariate analysis. The results identified that smoking status $(\mathrm{p}=0.008, \mathrm{HR}=1.895)$, tumor size $(\mathrm{p}=0.001, \mathrm{HR}=2.511), \operatorname{LNR}(\mathrm{p}=0.012, \mathrm{HR}=2.098)$, and
PLR ( $\mathrm{p}=0.01, \mathrm{HR}=1.962)$ were all found to be independent risk factors for early recurrence (Table 3).

\section{Recurrence Location in the ER and NER Group}

The proportion and comparison of recurrence sites between different groups are shown in Table 4. A total of 178 patients experienced recurrence after surgery. The most common recurrence site in the ER group was the bone. There were 18 patients $(26.1 \%)$ with bone metastases in ER group, significantly more frequent than 9 patients $(5.3 \%)$ in NER group $(p=0.001)$. The most common recurrence site in NER group was the lung. There were 35 patients $(20.7 \%)$ exhibited lung metastasis in the NER group, while $14(20.3 \%)$ had lung metastases in the ER group. Two or more metastases were found in 13 patients $(18.8 \%)$ in the ER group and 16 patients $(9.5 \%)$ in the NER group.

\section{Survival Analysis Findings}

The recurrence-free survival curves of all patients, ER and NER groups are shown in Figure 2A and B. The median RFS for overall patients was 23.2 months, with 3- and 5-year recurrence-free survival rates of $37.9 \%$ and $22.9 \%$, respectively. The median RFS in the ER group was 6.93 months which was significantly lower than that in the NER group [median 36.6 months, $(\mathrm{p}<0.0001)]$. For all patients, the median OS time was 58 months, with 3- and 5-year recurrence-free survival rates of $65.1 \%$ and $49.8 \%$ (Figure 2C). The median OS time for the ER and NER groups was 20.6 and 83.1 months, respectively $(\mathrm{p}<0.0001)$, and the ER group had 3- and 5-year survival rates of $31.9 \%$ and $16.1 \%$, compared with $78.0 \%$ and $62.5 \%$ in the NER group (Figure 2D).

\section{Construction of the Prediction Model}

The risk score of never smoker, tumor size $\leq 2.95$, LNR $\leq 0.16$ and PLR $\leq 139$ was 0 points, the risk score of 
Table 2 Univariate Analyses of Risk Factors Associated with Early Recurrence

\begin{tabular}{|c|c|c|c|c|}
\hline Variable & & HR & $95 \% \mathrm{Cl}$ & $P$ value \\
\hline Gender & Male vs Female & 1.643 & $1.001-2.697$ & 0.005 \\
\hline Age, years & $>65$ vs $\leq 65$ & 1.269 & $0.78-2.065$ & 0.338 \\
\hline Smoking status & Smoker vs Never smoker & 1.881 & $1.172-3.021$ & 0.009 \\
\hline Body mass index, $\mathrm{kg} / \mathrm{m} 2$ & $\begin{array}{l}18.5-25 \text { vs }<18.5 \\
\geq 25 \text { vs }<18.5 \\
18.5-25 \text { vs } \geq 25\end{array}$ & $\begin{array}{l}0.695 \\
0.439 \\
1.583\end{array}$ & $\begin{array}{l}0.316-1.528 \\
0.163-1.179 \\
0.781-3.209\end{array}$ & $\begin{array}{l}0.365 \\
0.102 \\
0.203\end{array}$ \\
\hline Histological subtype & $\begin{array}{l}S Q \text { vs } A D \\
\text { Other vs } A D \\
\text { SQ vs.Other }\end{array}$ & $\begin{array}{l}1.421 \\
2.4 \\
0.592\end{array}$ & $\begin{array}{l}0.845-2.39 \\
0.86 I-6.686 \\
0.203-1.725\end{array}$ & $\begin{array}{l}0.186 \\
0.094 \\
0.337\end{array}$ \\
\hline Tumor size, cm & $>2.95$ vs $\leq 2.95$ & 2.733 & $1.58-4.728$ & 0.0001 \\
\hline Surgery type & VATS vs Open & 0.566 & $0.352-0.908$ & 0.018 \\
\hline Extent of surgical resection & Lobectomy vs Pneumonectomy & 1.004 & $0.316-3.195$ & 0.994 \\
\hline Tumor localization & Right vs Left & 1.104 & $0.679-1.797$ & 0.69 \\
\hline $\mathrm{N}$ status & $\begin{array}{l}\mathrm{pN} 2 \mathrm{a} 2 \text { vs } \mathrm{pN} 2 \mathrm{al} \\
\mathrm{pN} 2 \mathrm{~b} \text { vs } \mathrm{pN} 2 \mathrm{al} \\
\mathrm{pN} 2 \mathrm{a} 2 \text { vs } \mathrm{pN} 2 \mathrm{~b}\end{array}$ & $\begin{array}{l}2.584 \\
2.2 \\
1.174\end{array}$ & $\begin{array}{l}1.244-5.365 \\
1.152-4.203 \\
0.672-2.053\end{array}$ & $\begin{array}{l}0.011 \\
0.017 \\
0.573\end{array}$ \\
\hline The number of examined lymph nodes & $>10$ vs $\leq 10$ & 1.591 & $0.885-2.861$ & 0.105 \\
\hline LNR & $>0.16$ vs $\leq 0.16$ & 1.816 & $1.025-3.218$ & 0.041 \\
\hline Adjuvant therapy & $\begin{array}{l}\text { Chemotherapy vs No } \\
\text { Targeted therapy vs No } \\
\text { Chemotherapy vs Targeted therapy }\end{array}$ & $\begin{array}{l}0.77 \\
0.463 \\
1.664\end{array}$ & $\begin{array}{l}0.458-1.296 \\
0.198-1.084 \\
0.745-3.715\end{array}$ & $\begin{array}{l}0.325 \\
0.076 \\
0.214\end{array}$ \\
\hline NLR & $>2.5 \mathrm{I}$ vs $\leq 2.5 \mathrm{I}$ & 1.853 & $1.156-2.972$ & 0.01 \\
\hline LMR & $>3.54$ vs $\leq 3.54$ & 0.699 & $0.433-1.127$ & 0.142 \\
\hline PLR & $>139$ vs $\leq 139$ & 2.426 & $1.47-4.006$ & 0.001 \\
\hline ALI & $>42.44$ vs $\leq 42.44$ & 0.524 & $0.32-0.856$ & 0.01 \\
\hline SII & $>327$ vs $\leq 327$ & 3.103 & I.484-6.486 & 0.003 \\
\hline $\mathrm{PNI}$ & $>48.6$ vs $\leq 48.6$ & 0.895 & $0.558-1.436$ & 0.646 \\
\hline
\end{tabular}

Abbreviations: ER, early recurrence; NER, non-early recurrence; VATS, video-assisted thoracoscopic surgery; AD, adenocarcinoma; SQ, squamous cell carcinoma; LNR, lymph node ratio; NLR, neutrophil-to-lymphocyte ratio; LMR, lymphocyte-to-monocyte ratio; PLR, platelet-to-lymphocyte ratio; ALI, advanced lung cancer inflammation index; SII, systemic immune-inflammation index; PNI, prognostic nutritional index.

Table 3 Multivariate Analyses of Risk Factors Associated with Early Recurrence

\begin{tabular}{|l|l|l|l|l|}
\hline Variable & HR & $\mathbf{9 5 \%}$ Cl & P value & Risk Score \\
\hline Smoking status (Smoker vs Never smoker) & 1.895 & $1.178-3.048$ & 0.008 & 2 vs 0 \\
Tumor size $(>2.95$ vs $\leq 2.95)$ & 2.511 & $1.43-4.409$ & 0.001 & 3 vs 0 \\
LNR $(>0.16$ vs $\leq 0.16)$ & 2.098 & $1.178-3.738$ & 0.012 & 2 vs 0 \\
PLR $(>139$ vs $\leq 139)$ & 1.962 & $1.173-3.28$ & 0.01 & 2 vs 0 \\
\hline
\end{tabular}

Abbreviations: $\mathrm{HR}$, hazard ratio; $\mathrm{Cl}$, confidence interval; LNR, lymph node ratio; PLR, platelet-to-lymphocyte ratio. 
Table 4 Sites of Recurrence After Curative Resection in the 178 Recurred Patients

\begin{tabular}{|l|l|l|l|}
\hline \multirow{2}{*}{ Recurrence Site } & ER Group & NER Group & \multirow{2}{*}{ P value } \\
\cline { 2 - 3 } & N=69 & N=109 & \\
\hline Single site & $56(81.2 \%)$ & $93(85.3 \%)$ & 0.464 \\
Lung & $14(20.3 \%)$ & $35(20.7 \%)$ & 0.085 \\
Brain & $7(10.1 \%)$ & $22(13.0 \%)$ & 0.077 \\
Lymph node & $10(14.5 \%)$ & $18(10.7 \%)$ & 0.718 \\
Bone & $18(26.1 \%)$ & $9(5.3 \%)$ & 0.001 \\
Chest wall & $1(1.4 \%)$ & $3(1.8 \%)$ & 0.568 \\
Pleura & $3(4.3 \%)$ & $1(0.6 \%)$ & 0.132 \\
Liver & $3(4.3 \%)$ & $2(1.2 \%)$ & 0.323 \\
Other & $0(0 \%)$ & $3(1.8 \%)$ & 0.165 \\
Multiple sites & $13(18.8 \%)$ & $16(9.5 \%)$ & 0.464 \\
\hline
\end{tabular}

Abbreviations: ER, early recurrence; NER, non-early recurrence.

smoker, LNR $>0.16$ and PLR $>139$ was 2 points and the risk score of tumor size $>2.95$ was 3 points (Table 3 ). The patients were further classified into three subgroups based on the value of total risk scores from four independent risk factors. Low-risk group included 74 patients (31.1\%) with risk score 0-3; median-risk group included 92 patients (38.7\%) with risk score 4-6; and high-risk group included 72 patients $(30.3 \%)$ with risk score $7-9$. The Kaplan-Meier curves of RFS and OS showed that a higher risk group was associated with shorter RFS and OS (Figure 3). The median RFS time in the low-, median-, and high-risk groups was 39.0, 18.9, and 10.5 months. The 3- and 5-year RFS rates in these group were $56.8 \%$ and $27.1 \%, 32.9 \%$ and $21.4 \%, 23.9 \%$ and $18.6 \%$, respectively. There was a significant difference between the groups $(p=0.001)$. The median OS time in the low-, median-, and high-risk groups was $83.5,48.0$, and 32.5 months, respectively. The low-risk group had 3- and 5-year OS rates of $87.7 \%$ and $71.4 \%$, compared with $60.9 \%$ and $48.2 \%, 48.6 \%$ and $32.6 \%$ in the median- and high-risk groups, respectively. These differences between groups were also significant $(\mathrm{P}$ $=0.001)$. Using this model to predict early recurrence, the AUC value obtained from ROC curve is $0.723(95 \%$ $\mathrm{CI}=0.654-0.793), \mathrm{p}<0.0001$, indicating that the prediction model has good discrimination ability.
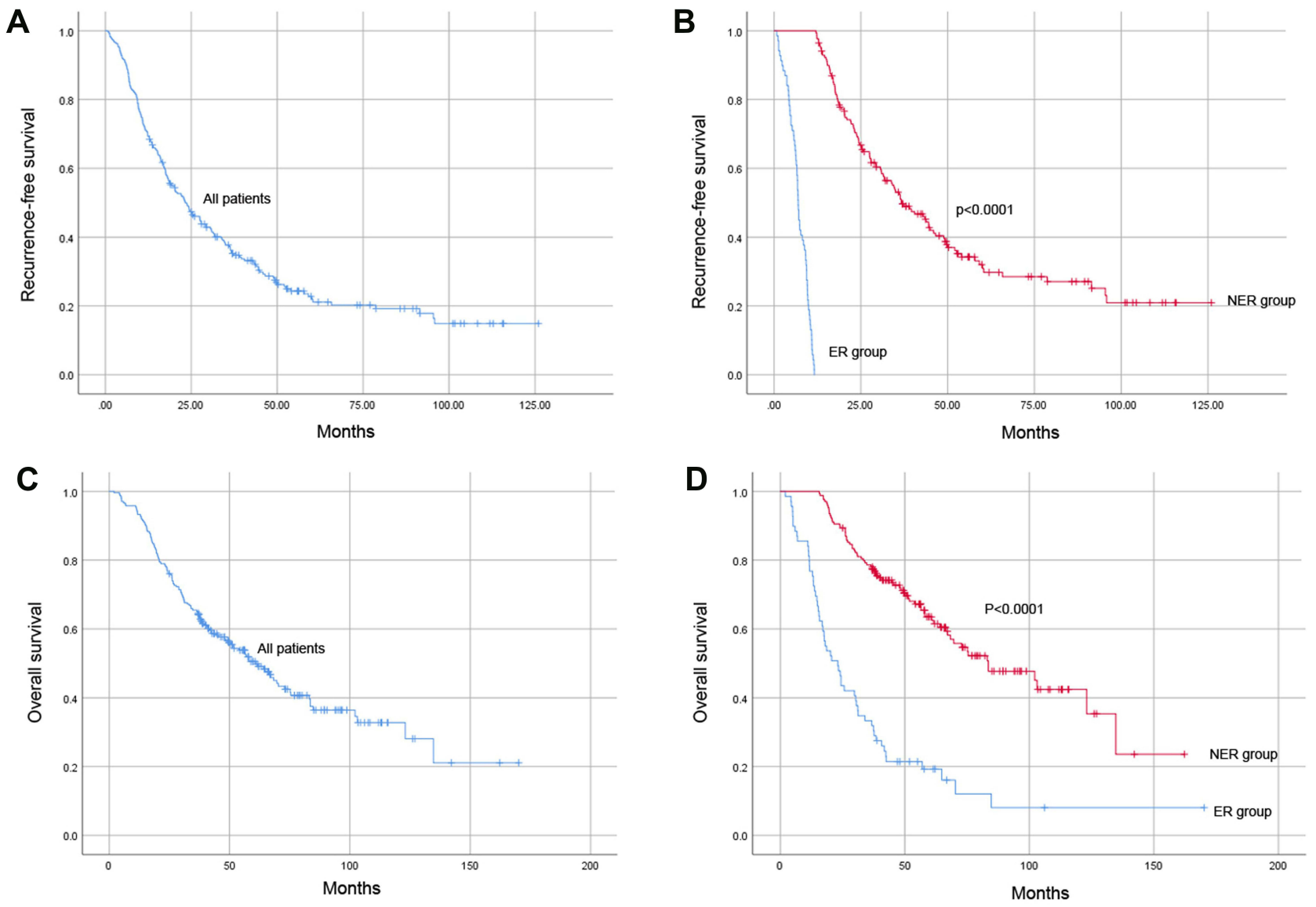

Figure 2 Kaplan-Meier survival curve for RFS (A and $\mathbf{B})$ and OS (C and $\mathbf{D})$ of overall patients and patients in ER and NER groups. 

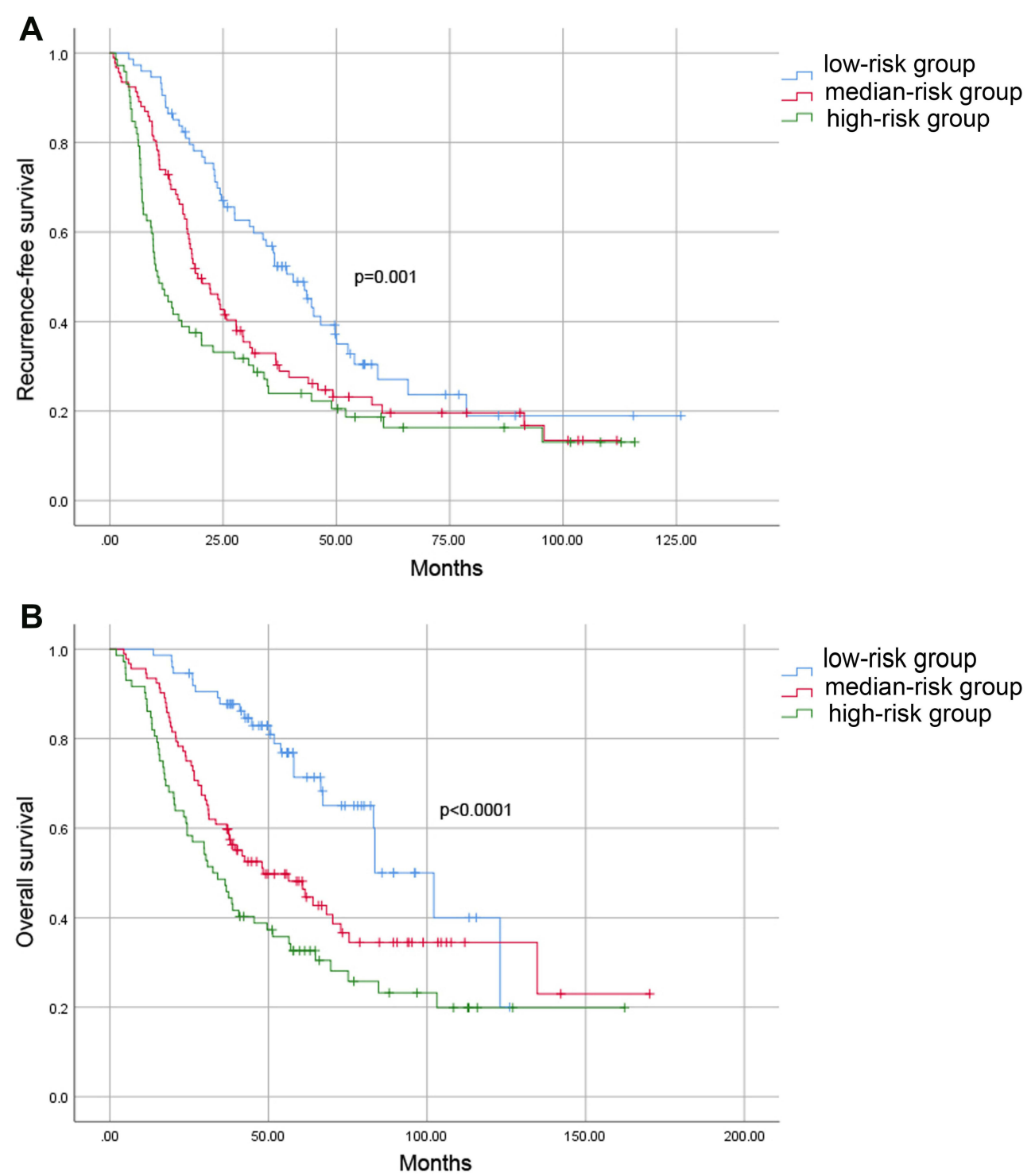

Figure 3 Kaplan-Meier survival curve for RFS (A) and OS (B) of patients with different risk groups.

\section{Discussion}

The overall 5-year OS and RFS rates of $49.8 \%$ and $22.9 \%$ in this study were quite similar to those reported by Hirofumi et al $(46 \%$ and $24 \%) .{ }^{31}$ Early postoperative recurrence in individuals with NSCLC has been linked to a poor prognosis in several studies. ${ }^{32}$ In our study, we reached the same conclusion, with the median OS for the ER and NER groups being 20.6 and 83.1 months, respectively. Therefore, it is critical to identify risk factors for early recurrence and this may improve the survival rate of patients with stage pIIIA-N2 NSCLC. Previous research, on the other hand, did not focus solely on prognosis factors for early recurrence. In this study, we analyzed the prognostic value of clinical, pathological, and biological features of 238 patients with stage pIIIA-N2 NSCLC. Our results indicated that smoking status, tumor size, LNR, and PLR are all independent risk factors for early recurrence.

Smoking is the major cause of lung cancer, with habitual smokers having a nearly 25 -fold greater risk of lung cancer compared to non-smokers. ${ }^{33}$ Furthermore, smokers account for approximately $90 \%$ of all lung cancer mortality. ${ }^{34}$ In addition, Wen et al indicated that smoking history is an independent predictor of RFS in NSCLC patients. ${ }^{16}$ Our study also found that early recurrence is more likely in smokers. To conclude, smoking not only increases the risk of lung cancer but also linked to early postoperative recurrence and a poor prognosis. Smokers 
should be educated about the need of quitting smoking and encouraged to participate more actively in postoperative follow-up.

Tumor size is a clinically validated predictive factor and a risk factor for cancer metastasis. Recurrence risk was significantly higher in patients with larger tumors of $30-50 \mathrm{~mm}$ compared to those with a medium tumor of 20 $30 \mathrm{~mm}$ in a research by Dariusz Adam et al. ${ }^{35}$ In another investigation, Hirofumi et al demonstrated that tumor size $>30 \mathrm{~mm}$ was an independent predictive factor for OS and RFS in pN2 NSCLC patients. ${ }^{31}$ Our study used a ROC curve analysis to determine the optimal cut-off value of $2.95 \mathrm{~cm}$ and discovered that tumor size $>2.95 \mathrm{~cm}$ was a statistically significant predictor than tumor size $\leq 2.95 \mathrm{~cm}$. This could be due to the fact that when the tumor is large, local invasion and metastasis are more likely to occur.

For patients with NSCLC, lymph node metastasis is another key prognostic predictor of survival. Several studies have demonstrated that LNR is a reliable predictor of survival and postoperative recurrence in resectable NSCLC patients with lymph node metastasis. ${ }^{36-39}$ However, the cut-off values of LNR differed among these reports, ranging from 0.12 to 0.34 . Our study is the first to specially demonstrate that LNR is an independent predictor of early recurrence in stage pIIIA-N2 NSCLC undergoing curative resection. The cut-off value used in our study was 0.16 . Patients with LNR $>0.16$ had almost double the risk of early recurrence compared to those with LNR $\leq 0.16(p=0.012)$. The relationship between $N$ status and prognosis remains controversial, Isaka et al found that pN2a1 had a statistically significant lower local recurrence rate than $\mathrm{pN} 2 \mathrm{a} 2{ }^{40}$ On the contrary, studies from Aksoy et al and Dziedzic et al found there was no significant difference in survival across patients with various $\mathrm{N}$ statuses. ${ }^{41,42}$ In our study, pN2al patients had a better RFS in univariate analysis than $\mathrm{pN} 2 \mathrm{a} 2$ and $\mathrm{pN} 2 \mathrm{~b}$ patients, however, no significant difference was identified in multivariate analysis.

Current guidelines propose adjuvant chemotherapy or adjuvant targeted therapy following surgery for patients with pIIIA-N2 NSCLC. In this study, the HR of recurrence in patients who underwent postoperative chemotherapy or targeted therapy was 0.77 and 0.463 , respectively, but not statistically significant. To identify the effects of different postoperative therapies on recurrence, larger sample size studies may be required.
Systemic inflammatory response plays a key role in cancer growth, development, invasion, and metastasis. ${ }^{43}$ Inflammatory biomarkers such as the NLR, LMR, PLR, ALI, and SII have recently been discovered to be effective indicators of prognosis in patients with NSCLC. ${ }^{23-26,28,29}$ However, the selection of these markers is under-defined and varied from study to study. NLR, PLR, ALI, and SII were found to be significant risk factors for early recurrence in the current study's univariate analysis, while PLR was the only independent factor in the multivariate. PLR $>139$ was linked to a greater probability of early recurrence in this study. To finally clarify which inflammatory signals are linked to early recurrence in stage pIIIA-N2 NSCLC, a large-scale study is required.

Incorporating pertinent clinical, pathological, and biological aspects into our investigation resulted in a muchimproved prediction model in our study. The predictive value of the model ( $\mathrm{AUC}=0.723$ ) is better than single independent risk factors compared to smoking status $(\mathrm{AUC}=0.584)$, tumor size $\quad(\mathrm{AUC}=0.634), \quad \mathrm{LNR}$ $(\mathrm{AUC}=0.575)$ and PLR $(\mathrm{AUC}=0.623)$. The data required by this model is easy to obtain and the scoring method is simple and convenient. Therefore, this model could be useful in identifying appropriate postoperative treatment for doctors in the future. Following the detection of a higher risk of recurrence, more proactive follow-up and therapy may be required. There is considerable discussion in the medical community about whether patients with pIIIA-N2 NSCLC should receive postoperative radiation. ${ }^{44-47}$ According to some studies, patients in the high-risk group should consider and may benefit from postoperative radiation. However, clinical evidence of its benefit is required to support the claim. Since the bone is the most common metastatic site for early recurrence in our study, it may be required to pay particular consideration to bone metastasis in high-risk individuals. For patients with median risk, the advantages and disadvantages according to the age and physical condition should be weighed to decide postoperative treatment. And for patients with low risk, treatment options may be inclined to be more conservative.

There were some limitations to the current investigation. First, this was a retrospective study conducted at a single institution with a limited sample size and therefore patient selection bias was inevitable Second, postoperative follow-up time was limited especially for patients diagnosed after 2017. Moreover, patients' postoperative follow-up intervals were varied. As a result, the recurrence 
time calculated may be inaccurate. To assess the significance of clinical, pathological, and biological variables in predicting early recurrence for patients with pIIIA-N2 NSCLC, more prospective multicenter studies with larger populations are needed.

\section{Conclusion}

In conclusion, early recurrence after complete resection is associated with a poor prognosis in patients with pIIIA-N2 NSCLC. Tumor size, smoking status, LNR, and PLR are all major risk factors for early recurrence. A prediction model was developed based on these four independent risk indicators, and it was useful in identifying patients at high risk. Our findings could be crucial in assessing personalized treatment options for patients.

\section{Data Sharing Statement}

All datasets used and analysed in this study are available from the authors on reasonable request.

\section{Ethics Approval}

The study was approved by the ethics committee of the First Affiliated Hospital of Wenzhou Medical University. Due to the retrospective nature of the study and the anonymity of all patient information, the ethics committee concluded that written informed consent was not necessary.

\section{Acknowledgments}

This work was supported by the National Natural Science Foundation of China (NO.81871318).

\section{Disclosure}

The authors report no conflicts of interest in this work.

\section{References}

1. Siegel RL, Miller KD, Jemal A. Cancer statistics, 2020. CA Cancer J Clin. 2020;70(1):7-30. doi:10.3322/caac.21590

2. Molina JR, Yang P, Cassivi SD, Schild SE, Adjei AA. Non-small cell lung cancer: epidemiology, risk factors, treatment, and survivorship. Mayo Clin Proc. 2008;83(5):584-594. doi:10.1016/S0025-6196(11)60735-0

3. Gillaspie EA, Wigle DA. Management of stage IIIA (N2) non-small cell lung cancer. Thorac Surg Clin. 2016;26(3):271-285. doi:10.1016/ j.thorsurg.2016.04.001

4. Darling GE, Li F, Patsios D, et al. Neoadjuvant chemoradiation and surgery improves survival outcomes compared with definitive chemoradiation in the treatment of stage IIIA N2 non-small-cell lung cancer. Eur J Cardiothorac Surg. 2015;48(5):684-690; discussion 690. doi:10.1093/ejcts/ezu504

5. Kim DW, Yun JS, Song SY, Na KJ. The prognosis according to patterns of mediastinal lymph node metastasis in pathologic stage IIIA/N2 non-small cell lung cancer. Korean $J$ Thorac Cardiovasc Surg. 2014;47(1):13-19. doi:10.5090/kjtcs.2014.47.1.13
6. Silvestri GA, Gonzalez AV, Jantz MA, et al. Methods for staging non-small cell lung cancer: diagnosis and management of lung cancer, 3rd ed: American College of Chest Physicians evidence-based clinical practice guidelines. Chest. 2013;143(5Suppl):e211S-e250S. doi:10.1378/chest.12-2355

7. Massard G, Renaud S, Reeb J, Santelmo N, Olland A, Falcoz PE. N2IIIA non-small cell lung cancer: a plea for surgery! J Thorac Dis. 2016;8(Suppl 11):S849-S854. doi:10.21037/jtd.2016.09.34

8. Feng W, Fu XL, Cai XW, et al. Patterns of local-regional failure in completely resected stage IIIA(N2) non-small cell lung cancer cases: implications for postoperative radiation therapy clinical target volume design. Int J Radiat Oncol Biol Phys. 2014;88(5):1100-1107. doi:10.1016/j.ijrobp.2013.12.048

9. Iwasaki A, Shirakusa T, Miyoshi T, et al. Prognostic significance of subcarinal station in non-small cell lung cancer with T1-3 N2 disease. Thorac Cardiovasc Surg. 2006;54(1):42-46. doi:10.1055/s-2005-865828

10. Dai H, Hui Z, Ji W, et al. Postoperative radiotherapy for resected pathological stage IIIA-N2 non-small cell lung cancer: a retrospective study of 221 cases from a single institution. Oncologist. 2011;16 (5):641-650. doi:10.1634/theoncologist.2010-0343

11. Yoo C, Yoon S, Lee DH, et al. Prognostic significance of the number of metastatic pN2 lymph nodes in stage IIIA-N2 non-small-cell lung cancer after curative resection. Clin Lung Cancer. 2015;16(6):e203212. doi:10.1016/j.cllc.2015.04.004

12. Nakagiri T, Sawabata N, Funaki $\mathrm{S}$, et al. Validation of $\mathrm{pN} 2$ sub-classifications in patients with pathological stage IIIA N2 non-small cell lung cancer. Interact Cardiovasc Thorac Surg. 2011;12(5):733-738. doi:10.1510/icvts.2010.249896

13. Ichinose $\mathrm{Y}$, Kato $\mathrm{H}$, Koike $\mathrm{T}$, et al. Overall survival and local recurrence of 406 completely resected stage IIIa-N2 non-small cell lung cancer patients: questionnaire survey of the Japan Clinical Oncology Group to plan for clinical trials. Lung Cancer. 2001;34 (1):29-36. doi:10.1016/S0169-5002(01)00207-0

14. Inoue M, Sawabata N, Takeda S, Ohta M, Ohno Y, Maeda H. Results of surgical intervention for p-stage IIIA (N2) non-small cell lung cancer: acceptable prognosis predicted by complete resection in patients with single N2 disease with primary tumor in the upper lobe. J Thorac Cardiovasc Surg. 2004;127(4):1100-1106. doi:10. 1016/j.jtcvs.2003.09.012

15. Wei W, Zhou J, Zhang Q, et al. Postoperative intensity-modulated radiation therapy reduces local recurrence and improves overall survival in III-N2 non-small-cell lung cancer: a single-center, retrospective study. Cancer Med. 2020;9(8):2820-2832. doi:10.1002/cam4. 2937

16. Feng W, Zhang Q, Fu XL, et al. The emerging outcome of postoperative radiotherapy for stage IIIA(N2) non-small cell lung cancer patients: based on the three-dimensional conformal radiotherapy technique and institutional standard clinical target volume. $B M C$ Cancer. 2015;15:348. doi:10.1186/s12885-015-1326-6

17. Noel G, Mazeron JJ, Wagner H. [A randomized trial of postoperative adjuvant therapy in patients with completely resected stage II or IIIa non-small-cell lung cancer]. Cancer Radiother. 2001;5(2):195-196. Dutch. doi:10.1016/S1278-3218(00)00066-4

18. Sawyer TE, Bonner JA, Gould PM, et al. The impact of surgical adjuvant thoracic radiation therapy for patients with nonsmall cell lung carcinoma with ipsilateral mediastinal lymph node involvement. Cancer. 1997;80(8):1399-1408. doi:10.1002/(SICI)1097-0142(19971 015)80:8<1399::AID-CNCR6>3.0.CO;2-A

19. Zhang B, Zhao L, Yuan Z, Pang Q, Wang P. The influence of the metastasis pattern of mediastinal lymph nodes on the postoperative radiotherapy's efficacy for the IIIA-pN2 non-small-cell lung cancer: a retrospective analysis of 220 patients. Onco Targets Ther. 2016;9:6161-6169. doi:10.2147/OTT.S103565

20. Mantovani A, Allavena P, Sica A, Balkwill F. Cancer-related inflammation. Nature. 2008;454(7203):436-444. doi:10.1038/nature 07205 
21. Colotta F, Allavena P, Sica A, Garlanda C, Mantovani A. Cancerrelated inflammation, the seventh hallmark of cancer: links to genetic instability. Carcinogenesis. 2009;30(7):1073-1081. doi:10.1093/carcin/bgp 127

22. Elinav E, Nowarski R, Thaiss CA, Hu B, Jin C, Flavell RA. Inflammation-induced cancer: crosstalk between tumours, immune cells and microorganisms. Nat Rev Cancer. 2013;13(11):759-771. doi: $10.1038 / \mathrm{nrc} 3611$

23. Takahashi Y, Kawamura M, Hato T, Harada M, Matsutani N, Horio H. Neutrophil-lymphocyte ratio as a prognostic marker for lung adenocarcinoma after complete resection. World J Surg. 2016;40(2):365-372. doi:10.1007/s00268-015-3275-2

24. Jiang G, Huang J, Cui T, Lin X, Lin G. A biomarker-based prediction model for risk of locoregional recurrence in pathologic stage IIIA-N2 non-small cell lung cancer. Int J Clin Exp Pathol. 2020;13 (12):3060-3082.

25. Wang YQ, Zhi QJ, Wang XY, Yue DS, Li K, Jiang RC. Prognostic value of combined platelet, fibrinogen, neutrophil to lymphocyte ratio and platelet to lymphocyte ratio in patients with lung adenosquamous cancer. Oncol Lett. 2017;14(4):4331-4338. doi:10.3892/ol.2017.6660

26. Sanchez-Salcedo P, De-torres JP, Martinez-Urbistondo D, et al. The neutrophil to lymphocyte and platelet to lymphocyte ratios as biomarkers for lung cancer development. Lung Cancer. 2016;97:28-34. doi:10.1016/j.lungcan.2016.04.010

27. Yamauchi Y, Safi S, Muley T, et al. C-reactive protein-albumin ratio is an independent prognostic predictor of tumor recurrence in stage IIIA-N2 lung adenocarcinoma patients. Lung Cancer. 2017;114:62-67. doi:10.1016/j.lungcan.2017.11.002

28. Jafri SH, Shi R, Mills G. Advance lung cancer inflammation index (ALI) at diagnosis is a prognostic marker in patients with metastatic non-small cell lung cancer (NSCLC): a retrospective review. $B M C$ Cancer. 2013;13:158. doi:10.1186/1471-2407-13-158

29. Guo W, Cai S, Zhang F, et al. Systemic immune-inflammation index (SII) is useful to predict survival outcomes in patients with surgically resected non-small cell lung cancer. Thorac Cancer. 2019;10 (4):761-768. doi:10.1111/1759-7714.12995

30. Shoji F, Morodomi Y, Akamine T, et al. Predictive impact for postoperative recurrence using the preoperative prognostic nutritional index in pathological stage I non-small cell lung cancer. Lung Cancer. 2016;98:15-21. doi:10.1016/j.lungcan.2016.05.010

31. Uehara H, Nakao M, Mun M, et al. Significant prognostic factors for completely resected pN2 non-small cell lung cancer without neoadjuvant therapy. Ann Thorac Cardiovasc Surg. 2015;21(4):345-353. doi:10.5761/atcs.oa.14-00262

32. Kobayashi S, Karube Y, Matsumura Y, et al. Inflammatory risk factors for early recurrence of non-small cell lung cancer within one year following curative resection. World J Surg. 2020;44 (10):3510-3521. doi:10.1007/s00268-020-05612-0

33. US Department of Health and Human Services. The health consequences of smoking-50 years of progress: a report of the surgeon general. Atlanta (GA). 2014.

34. Picciotto MR, Kenny PJ. Molecular mechanisms underlying behaviors related to nicotine addiction. Cold Spring Harb Perspect Med. 2013;3(1):a012112. doi:10.1101/cshperspect.a012112
35. Dziedzic DA, Rudzinski P, Langfort R, Orlowski T; Polish Lung Cancer Study Group. Risk factors for local and distant recurrence after surgical treatment in patients with non-small-cell lung cancer. Clin Lung Cancer. 2016;17(5):e157-e167. doi:10.1016/j. cllc. 2015.12 .013

36. Ohtaki Y, Shimizu K, Kaira K, et al. Risk factors associated with recurrence of surgically resected node-positive non-small cell lung cancer. Surg Today. 2016;46(10):1196-1208. doi:10.1007/s00595015-1301-5

37. Borghetti P, Barbera F, Bonu ML, et al. Resected pN1 non-small cell lung cancer: recurrence patterns and nodal risk factors may suggest selection criteria for post-operative radiotherapy. Radiol Med. 2016;121(9):696-703. doi:10.1007/s11547-016-0648-z

38. Matsuguma H, Oki I, Nakahara R, et al. Proposal of new nodal classifications for non-small-cell lung cancer based on the number and ratio of metastatic lymph nodes. Eur J Cardiothorac Surg. 2012;41(1):19-24. doi:10.1016/j.ejcts.2011.04.016

39. Taylor MD, LaPar DJ, Thomas CJ, et al. Lymph node ratio predicts recurrence and survival after R0 resection for non-small cell lung cancer. Ann Thorac Surg. 2013;96(4):1163-1170. doi:10.1016/j. athoracsur.2013.04.031

40. Isaka M, Kojima H, Takahashi S, Omae K, Ohde Y. Risk factors for local recurrence after lobectomy and lymph node dissection in patients with non-small cell lung cancer: implications for adjuvant therapy. Lung Cancer. 2018;115:28-33. doi:10.1016/j.lungcan.2017.11.014

41. Aksoy Y, Citak N, Obuz C, Metin M, Sayar A. Does anatomical location-based metastatic lymph node density affect prognosis in lung cancer patients? Interact Cardiovasc Thorac Surg. 2021;33:541-549. doi:10.1093/icvts/ivab119

42. Dziedzic DA, Cackowski MM, Zbytniewski M, et al. The influence of the number of lymph nodes removed on the accuracy of a newly proposed $\mathrm{N}$ descriptor classification in patients with surgically-treated lung cancer. Surg Oncol. 2021;37:101514. doi:10.1016/j.suronc.2020.12.008

43. Candido J, Hagemann T. Cancer-related inflammation. J Clin Immunol. 2013;33(Suppl 1):S79-84. doi:10.1007/s10875-012-9847-0

44. Lei T, Li J, Zhong $\mathrm{H}$, et al. Postoperative radiotherapy for patients with resectable stage III-N2 non-small cell lung cancer: a systematic review and meta-analysis. Front Oncol. 2021;11:680615. doi:10.3389/fonc.2021.680615

45. Hui Z, Men Y, Hu C, et al. Effect of postoperative radiotherapy for patients with pIIIA-N2 non-small cell lung cancer after complete resection and adjuvant chemotherapy: the phase 3 PORT-C randomized clinical trial. JAMA Oncol. 2021;7 (8):1178-1185. doi:10.1001/jamaoncol.2021.1910

46. Xu L, Xie HN, Chen XK, Bi N, Qin JJ, Li Y. Patient prognostic scores and association with survival improvement offered by postoperative radiotherapy for resected IIIA/N2 non-small cell lung cancer: a population-based study. Thorac Cancer. 2021;12(6):760-767. doi:10.1111/1759-7714.13835

47. Tian C, Liu G, Xu Y, et al. Postoperative radiotherapy for patients with completely resected pathological stage IIIA-N2 non-small cell lung cancer: a preferential benefit for squamous cell carcinoma. Radiol Oncol. 2020;55(1):66-76. doi:10.2478/raon-2020-0070
Cancer Management and Research

\section{Publish your work in this journal}

Cancer Management and Research is an international, peer-reviewed open access journal focusing on cancer research and the optimal use of preventative and integrated treatment interventions to achieve improved outcomes, enhanced survival and quality of life for the cancer patient.
The manuscript management system is completely online and includes a very quick and fair peer-review system, which is all easy to use. Visit http://www.dovepress.com/testimonials.php to read real quotes from published authors. 